\title{
o-Phenylenediamine encapsulated silver nanoparticles and their applications for organic light-emitting devices
}

\author{
Chang-Sik Ha ${ }^{*}$, Jin-Woo Park ${ }^{1}$ and Md. Habib Ullah ${ }^{2}$ \\ ${ }^{1}$ Department of Polymer Science and Engineering, Pusan National University \\ Busan 609-735, Korea \\ ${ }^{2}$ Department of Physics, American International University-Bangladesh (AIUB), \\ 94, Road 4, Kemal Ataturk Avenue, Banani, Dhaka, Bangladesh
}

\section{Introduction}

Quantum-size ( $<10 \mathrm{~nm}$ ) metal nanoparticles (NPs) have attracted a great deal of interest for a variety of applications (Gittins \& Caruso, 2001; Brust \& Kiely, 2002), many of which require that the particles be water-soluble(Ackerson, et al. 2005; Kim, et al., 2005; Bao, et al. 2003; Manna, et al. 2001) or remain suspended in water with no loss of their physical or chemical properties over extended periods of time. In addition, many applications require colloidal precipitation (Li, et al. 2005; Pan \& Rothberg, 2005; Haes \& Van Duyne, 2004) of these NPs to allow them to be film-cast using suitable solvents. The choice of synthetic methods and precursor elements are vitally important for determining the phase (watersoluble or colloidal precipitation) of the NPs. Water-based syntheses of NPs, however, are fraught with problems that result from ionic interactions, which are typically overcome by using very low reactant concentrations (ca. $1 \times 10^{-4} \mathrm{M}$ ) (Ahmadi, et al. 1996). Moreover, diffusion, which is much faster in aqueous solutions, can lead to aggregated metal NPs in the absence of a stabilizer (Rele, et al. 2004). In contrast, particles synthesized in suitable organic solvents can be prepared at relatively high concentrations of reactants (Sun \& Xia, 2002), with predefined sizes and shapes (Gree \& O'Brien, 1999; Pileni, 1998), and with improved monodispersity relative to that of NPs prepared in aqueous solutions.

Here, we describe the preparation of stable, monodisperse, quantum-sized silver nanoparticles (NPs) in water soluble form through a simple one-pot procedure that uses glycerol for reducing $\mathrm{Ag}^{+}$in the presence of o-phenylenediamine (o-PDA) (Habib, et al., 2006).

On the other hand, organic light emitting devices (OLEDs) have attracted great attention for flat panel display (FPD) applications due to their sophisticated device structure that is simpler than liquid crystal displays (LCD) as well as their fast response time and wide viewing angle which are similar to the typical cathode ray tube (CRT) display (Hung \& Chen, 2002).

OLEDs are commonly fabricated on glass substrates coated with a thin film of indium tin oxide (ITO). The ITO glass is generally employed as the anode in OLEDs because of its good 
electrical conductivity, high transparency over the visible region, ease of patterning, and relatively high work function. However, it has been suggested that the inefficiency of hole injection from bare ITO, poor adhesion at the ITO-organic film interface, and the diffusion of materials across the ITO-organic interface have led to the poor device performance of OLEDs (Kim, et al. 1998; Kugler, et al. 1998; Mason, et al. 1999). As a result, great effort has been made to modify the ITO anode, such as various treatments of the ITO surface and the deposition of very thin buffer layers between the ITO and the hole transport layer in order to enhance the OLED performances. In particular, poly(3,4-ethylene dioxythiophene)/ polystyrene sulfonic acid (PEDOT/PSS) is in the limelight because of high conductivity, stability, and transparency (Groenedaal, et al. 2000). In this aspect, we also investigated the performance of OLEDs by systematic incorporation of these Ag NPs in PEDOT/PSS matrix, which is used as a hole-injection layer for OLEDs (Park, et al. 2007).

\section{Experimental}

All chemical used were of analytical grade and purchased form Sigma-Aldrich. In a typical synthesis, $o$-PDA flakes $(0.40 \mathrm{~g})$ were dissolved in glycerol $(24 \mathrm{~mL})$ by heating at $140-160{ }^{\circ} \mathrm{C}$ for $30 \mathrm{~min}$ under vigorous magnetic stirring. The formation of a transparent light-green solution $(0.154 \mathrm{M})$ indicated that o-PDA had completely dissolved. Meanwhile, $\mathrm{AgNO}_{3}(1.0$ g) was dissolved in glycerol $(8 \mathrm{~mL})$ over $15 \mathrm{~min}$ at $90-100{ }^{\circ} \mathrm{C}$ under magnetic stirring; once a clear solution $(0.735 \mathrm{M})$ had formed, the stirring was continued for another $15 \mathrm{~min}$. The hot colloidal $\mathrm{Ag}(0)$ solution was then added dropwise continually into the solution of o-PDA. Heating of the reaction mixture was continued at $140-160{ }^{\circ} \mathrm{C}$ for $15 \mathrm{~min}$ and then the reaction mixture was quenched in cold $\left(0-2{ }^{\circ} \mathrm{C}\right)$ water $[1.6 \mathrm{~L} ; 50$ times the solvent volume (32 $\mathrm{ml})$ ]. We adopted a direct quenching technique (pouring the reaction mixture in cold water) to prevent aggregation because of highly concentrated particles being aggregated due to slow cooling. The colloidal mixture was maintained under static conditions for $48 \mathrm{~h}$ (room temperature) to effect complete precipitation. The precipitated product was separated by decantation and washed several times with water. The decanted silver solution was then subjected to centrifugation, but no further precipitation or phase separation occurred. We termed this phase as a 'water-soluble'. Details of the single-phase solution product are described elsewhere (Habib, et al., 2006).

PEDOT/PSS (2.8 wt\% dispersed in $\mathrm{H}_{2} \mathrm{O}$ ) was purchased from Aldrich. It was filtered through a $0.45 \mu \mathrm{m}$ membrane filter (Millipore, PVDF) before preparing a hybrid solution. Tris(8-hydroxyquinolinato)aluminum (Alq3) and $N, N^{\prime}$-diphenyl- $N, N^{\prime}$-bis(3-methylphenyl)1,1-biphenyl-4,4'-diamine) (TPD) were purchased from Tokyo Kasei Kogyo Co., Ltd. and used without further purification.

Hybrid PEDOT/PSS-Ag solutions were prepared by dispersing a given mass ratios of $o$ PDA encapsulated Ag NPs in the aqueous PEDOT/PSS solution in an ultrasonic bath for $4 \mathrm{~h}$. Three different weight ratios (5, 10, and $20 \mathrm{wt} \%$ ) of these Ag NPs were employed to investigate the influence of composition. For the fabrication of OLEDs, ITO coated glass substrates were patterned in a strip of size $(2 \times 30 \mathrm{~mm})$ and were cleaned ultrasonically in deionized water using a non-phosphorus detergent and then rinsed with ethanol before drying. A layer of PEDOT/PSS-Ag nanocomposite (thickness $=40 \mathrm{~nm}$ ) was spin-coated onto the pre-cleaned ITO coated glass at $4000 \mathrm{rpm}$ for $60 \mathrm{~s}$ and then soft-baked at $100{ }^{\circ} \mathrm{C}$ for $6 \mathrm{~h}$ in a vacuum oven. On top of the PEDOT/PSS-Ag nanocomposite layer, a $50 \mathrm{~nm}$ TPD 
layer and a $60 \mathrm{~nm}$ thick $\mathrm{Alq}_{3}$ layer were deposited as a hole transporting layer and an emission layer, respectively, and finally cathode layer of aluminum (Al) was deposited by vacuum evaporation ( $5 \times 10^{-6}$ Torr) technique (as shown in Fig. 1), defining the active emission area of $4 \mathrm{~mm}^{2}$. For comparison, the device with the following structure was also prepared; PEDOT/PSS (thickness $=40 \mathrm{~nm}$ ) $/ \mathrm{TPD}$ (thickness $=50 \mathrm{~nm}$ ) $/ \mathrm{Alq}_{3}$ (thickness $=60 \mathrm{~nm}$ ) $/ \mathrm{Al}$ (see Fig. 1).

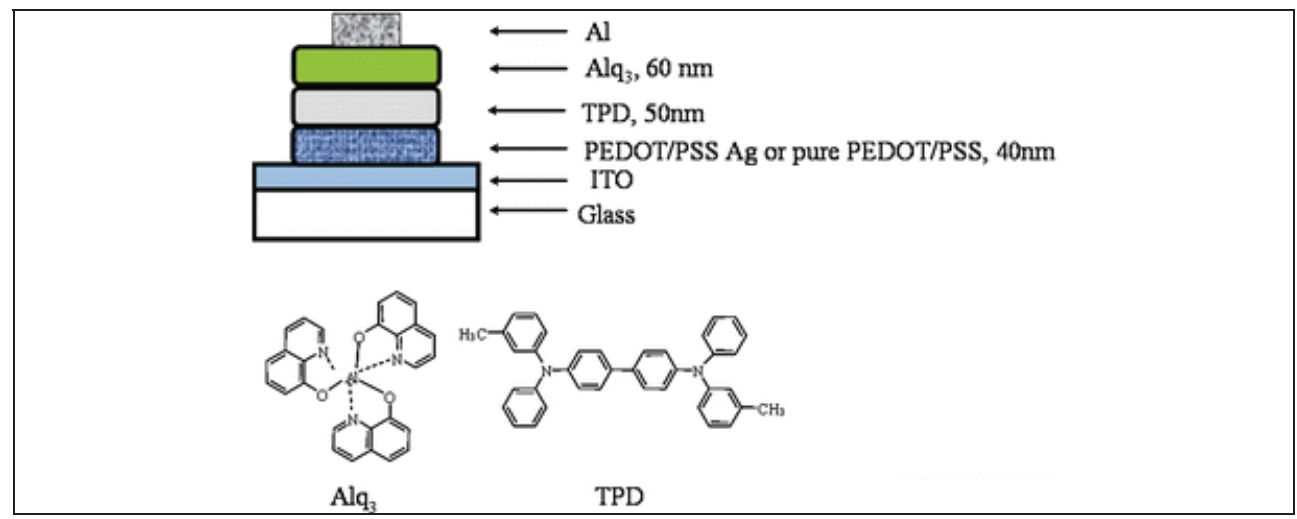

Fig. 1. Schematic cross-sectional structure of OLED used in this study and chemical structures of $\mathrm{Alq}_{3}$ and TPD (Park, et al. 2007).

The current density-voltage-luminance (J-V-L) characteristics of OLEDs were measured using a customized device measurement system equipped with a photomultiplier tube (PMT, Hamamatsu Photonics Co.) and an electrometer (SMU 236, Keithley). All devices were mounted in a dark sample chamber for the J-V-L measurements in order to get rid of any influence of ambient light.

\section{Results and Discussion}

Figure 2 displays a typical TEM image of the water-soluble Ag NPs. The nanoparticles exhibit a bimodal distribution, with distinct size ranges of 2-3 and 5-6 nm (Habib,et al.) (Habib, et al., 2006). We verified the TEM results through an analysis of the sample's UVVis absorption spectra. The water-soluble Ag NPs displayed a strong plasmon absorbance $(\lambda \max =448 \mathrm{~nm})$ possessing a bimodal-type pattern (Taubert, et al. 2003); XRD data (Figure 3) of Ag NPs displayed strong Bragg reflections corresponding to the (111), (200), (220), and (311) reflection planes of fcc metallic silver. 


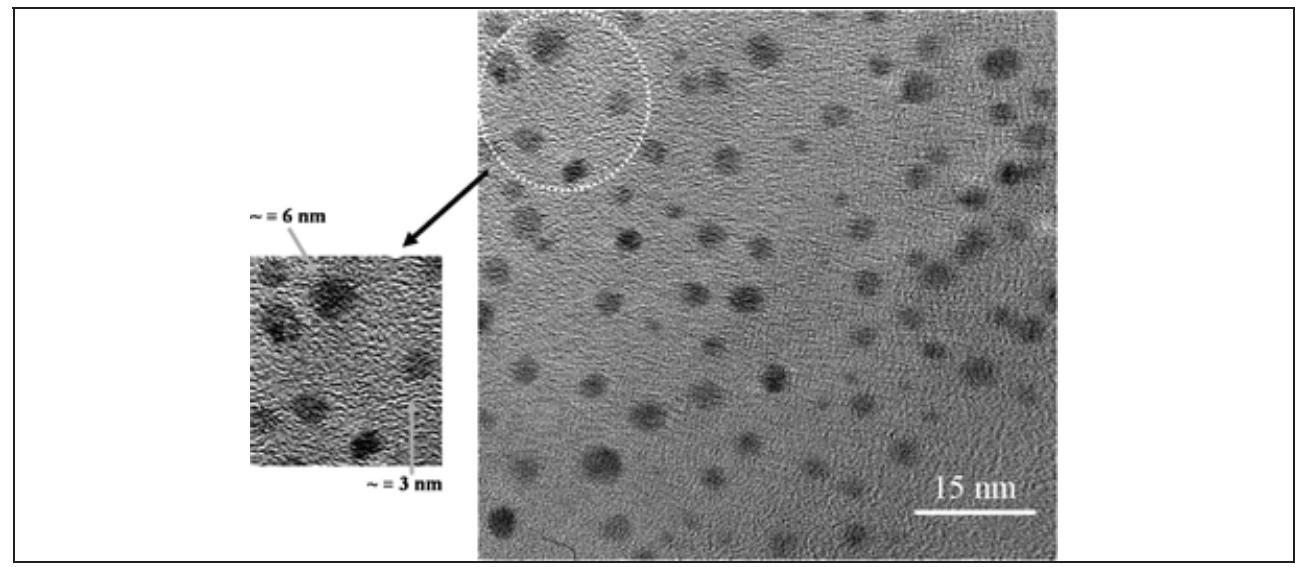

Fig. 2. TEM image of the water-soluble Ag NPs (Park, et al. 2007).

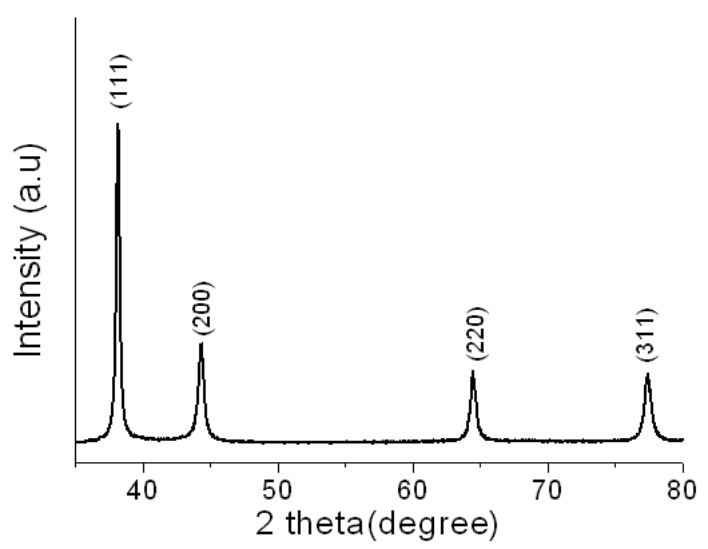

Fig. 3. XRD pattern of Ag NPs, displaying strong Bragg reflections corresponding to fcc metallic silver (Habib, et al. 2006).

The UV-Vis spectrum (Figure 4) of silver sol (prior to addition into the o-PDA solution) indicates that initially the particle sizes are $<2 \mathrm{~nm}$ (Wilson, et al. 2005; Kim, et al. 2004), they may be stabilized temporarily through complexion with hydroxypyruvic acid (i.e., oxidized glycerol) and glycerol (Rele, et al. 2004). Relatively larger particles were formed after adding the mixture into the o-PDA solution. This finding may indicate that when the small $(<2 \mathrm{~nm})$ particles entered into the comparatively hot $\left(140-160{ }^{\circ} \mathrm{C}\right) o$-PDA solution, they became uncapped from their temporary complexes and underwent a melting-like process to form relatively larger particles (Pastoriza-Santos \& Liz-Marzan, 2002). 


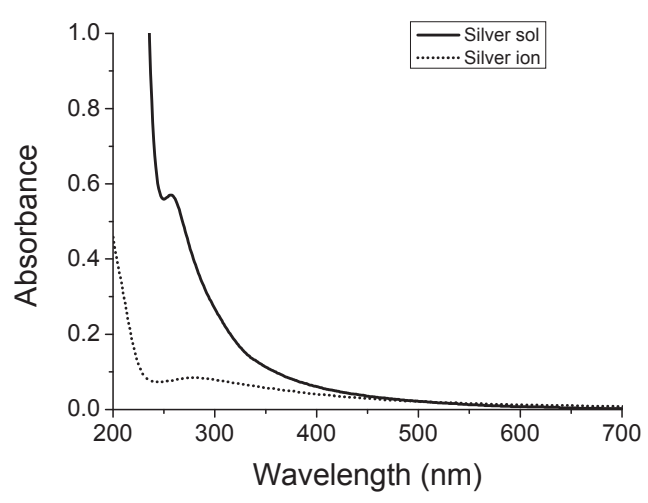

Fig. 4. The UV-Vis spectrum of silver sol prior to addition into o-PDA solution, which exhibits a monotonically increasing absorbance toward higher energies because, for very small particles, the distinctive plasmon band is replaced by a featureless absorbance, which has been compared with silver ion sol (Habib, et al. 2006).

Figure 5 presents the UV-vis absorption spectra of the PEDOT/PSS and the PEDOT/PSSAg nanocomposites with different concentrations of Ag NPs. o-PDA encapsulated watersoluble Ag NPs display a surface plasmon absorption band centered at $448 \mathrm{~nm}$, which is large red shift compared to the uncapped metallic silver that has an intense plasmon absorption band in the visible region at $\approx 390 \mathrm{~nm}$ (He et al. 2001; Kumar et al. 2003). The UVvis absorption coefficient (at wavelength $\approx 450 \mathrm{~nm}$ ) of the PEODT/PSS-Ag nanocomposite increases with increasing the concentration of Ag NPs, where pure PEDOT/PSS does not show any plasmon band. This result indicates that $o$-PDA encapsulated silver NPs are well embedded in the composite layer.

Current density (J)-voltage (V) and luminance (L)-voltage (V) characteristics of various devices fabricated in this work are shown in Fig. 6 (Park et al. 2007). As expected, the TPD/Alq3 device (see (a) curves in Figs. 6A and 6B) without PEODT/PSS layer exhibits the poorest performance among the devices. It is noteworthy that the performance of the OLEDs is significantly improved (see (c), (d), and (e) curves in Figs. 6A and B when the PEDOT/PSS-Ag nanocomposite layer (with the loading concentrations of Ag NPs in the range of 5-20 wt\%) is used compared to the OLED (see (b) curves in Figs. 6A and B) using PEDOT/PSS only as a hole injection layer. The devices with 10 or $20 \mathrm{wt} \%$ Ag NPs and PEDOT/PSS in the hole injection layer exhibited high brightness ((Fig. 6B). The turn-on voltages, 6.0, 7.8, 8.0, and $8.7 \mathrm{~V}$, were obtained for the loading of 20, 10, 5, $0 \mathrm{wt} \% \mathrm{Ag}$, respectively; where the turn-on voltage, $14 \mathrm{~V}$ was measured for the OLED without PEDOT/PSS. These results demonstrate that the turn-on voltage decreases with increasing the Ag NPs' concentration. In this work, the maximum luminance of the device fabricated with $20 \mathrm{wt} \%$ Ag nanoparticles in the PEDOT/PSS matrix as a hole injection layer was ca. $9,000 \mathrm{~cd} / \mathrm{m}^{2}$ at around $16 \mathrm{~V}$ (see (e) curve in Fig. 6B). 


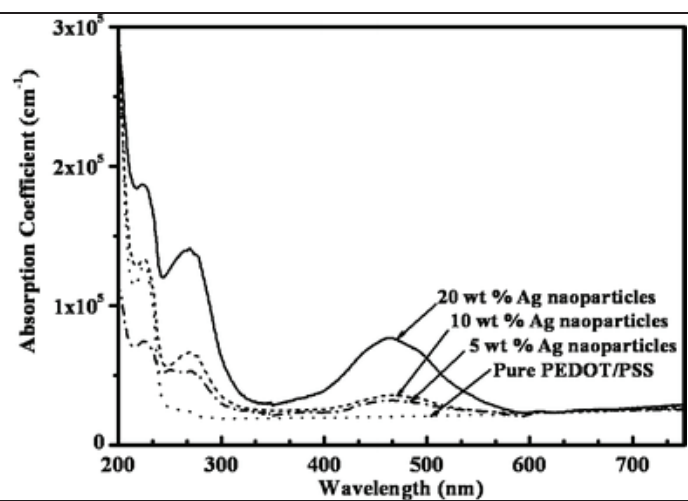

Fig. 5. UV-vis absorption spectra of the PEDOT/PSS and the PEDOT/PSS-Ag nanocomposites with different concentrations of Ag NPs in the PEDOT/PSS matrix (Park, et al. 2007).
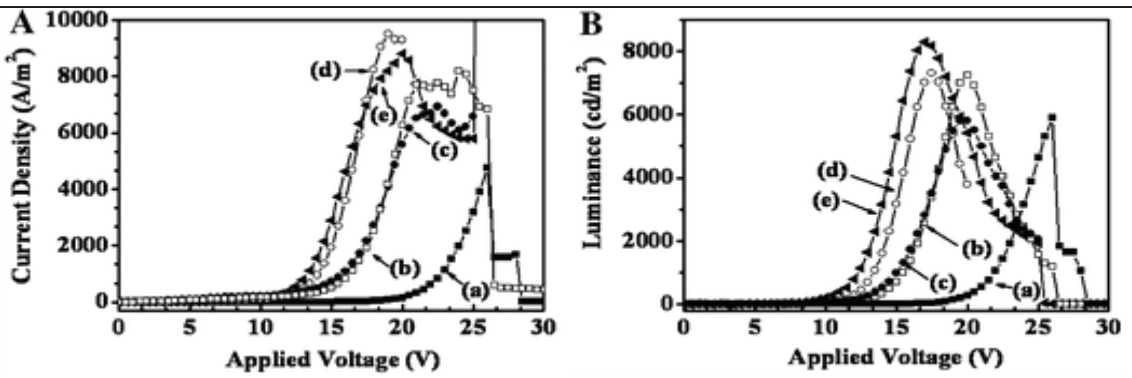

Fig. 6 (A) Current density-voltage and (B) luminance-voltage characteristics of OLEDs made with the PEDOT/PSS and the PEDOT/PSS-Ag nanocomposites with different concentrations of Ag NPs in the PEDOT/PSS matrix in the hole injection layer [(a) OLED without PEDOT/PSS, (b) OLED with PEDOT/PSS only, (c) PEDOT/PSS-Ag nanocomposite with $5 \mathrm{wt} \%$ Ag NPs, (d) PEDOT/PSS-Ag nanocomposite with $10 \mathrm{wt} \%$ Ag NPs, (e) PEDOT/PSS-Ag nanocomposite with 20 wt\% Ag NPs] (Park, et al. 2007).

Further study is, however, needed in order to understand more exact relationship between the optimum concentration and size of the Ag nanoparticles and the device performances.

\section{Conclusions}

We have synthesized aggregation free quantum-size silver NPs using a high $\mathrm{AgNO}_{3}$ concentration through a novel technique. The in-situ production of binary phases quantumsize Ag NPs having narrow size distributions will open the new avenue for the applied fields. The nanoparticles, especially, water-soluble Ag NPs are suitable for electronics applications because the $\pi$-conjugated aromatic amine molecules are well-coordinated with silver surface. In this sense, we investigated the performance of OLEDs consisting of PEDOT/PSS-Ag nanocomposites with different concentrations of quantum-size silver NPs as a hole injection layer. We found that the OLEDs with PEDOT/PSS-Ag nanocomposites 
exhibit improved performance. The turn-on voltage is significantly decreased when increasing the Ag NPs' concentration. In this work, the maximum luminance of the device consisting of $20 \mathrm{wt} \% \mathrm{Ag}$ NPs in the PEDOT/PSS matrix as a hole injection layer was ca. $9,000 \mathrm{~cd} / \mathrm{m}^{2}$ at around $16 \mathrm{~V}$.

\section{Acknowledgements:}

This work was supported by the National Research Foundation of Korea (NRF) Grant funded by the Ministry of Education, Science and Technology, Korea (MEST) (Acceleration Research Program (No. 2009-0078791)), and the Brain Korea 21 Project of the MEST.

\section{References}

Ackerson, C. J., Jadzinsky, P. D. \& Kornberg, R. D. (2005). Thiolate ligands for synthesis of water-soluble gold clusters. J. Am. Chem. Soc., 127, 18, 6550-6551, ISSN 0002-7863

Ahmadi, T. S., Wang, Z. W., Green, T. C., Henglein, A. \& El-Sayeed, M. A. (1996). Shapecontrolled synthesis of colloidal platinum nanoparticles. Science, 272, 5270, 19241925, ISSN 0036-8075

Bao, C., Jin, M., Lu, R., Xue, P., Zhang, T., Tan, C. \& Zhao, Y. (2003). Synthesis of hyperbranched poly(amine-ester)-protected noble metal nanoparticles in aqueous solution. J. Mater. Res., 18, 6, 1392-1398, ISSN 0884-2914

Brust, M. \& Kiely, C. (2002). Some recent advances in nanostructure preparation from gold and silver particles: a short topical review. J. Colloids Sur. A, 202, 2-3, 175-186, ISSN 0927-7757

Gittins, D. I. \& Caruso, F. (2001). Spontaneous Phase Transfer of nanoparticulate metals from organic to aqueous media, Angew. Chem. Int. Ed., 40, 16, 3001-3004, ISSN 14337851

Green, M. \& O'Brien, P. (1999). Recent advances in the preparation of semiconductors as isolated nanometric particles: new routes to quantum dots. Chem. Commun., 22, 2235-2241, ISSN 1359-7345

Groenedaal, L., Jonas, F., Freitag, D., Pielartzik, H. \& Reynolds, J. R. (2000). Poly(3,4ethylenedioxythiophene) and its derivatives: past, present, and future. Adv. Mater., 12, 7, 481-494, ISSN 0935-9548

Habib, M. H., Kim, I. \& Ha, C. S. (2006). In-situ preparation of binary-phase silver nanoparticles at a high Ag+ concentration. J. Nanosci. Nanotechnol., 6(3), 777 -782. ISSN 1533-4880.

Haes, A. J. \& Van Duyne, R. P. (2004). A unified view of propagating and localized surface plasmon resonance biosensors. Anal. Bioanal. Chem., 379, 7-8, 920-930, ISSN 1618-2642

He, S., Yao, J., Jiang, P., Shi, D., Zhang, H., Xie, S., Pang, S. \& Gao, H. (2001). Formation of silver nanoparticles and self-assembled two-dimensional ordered superlattice. Langmuir, 17, 5, 1571-1575, ISSN 0743-7463

Hung, L. S. \& Chen, C. H. (2002). Recent progress of molecular organic electroluminescent materials and devices. Mater. Sci. Eng. Rep., 39, 5-6, 143-222, ISSN 0927-796X

Kim, J. S., Granstrom, M., Friend, R. H., Johansson, N., Salaneck, W. R., Daik, R., Feast, W. J. \& Cacialli, F. (1998). Indium-tin oxide treatments for single- and double-layer polymeric light-emitting diodes: The relation between the anode physical, chemical, and morphological properties and the device performance. J. Appl. Phys., 84, 12, 6859-6870, ISSN 0921-8979 
Kim, S. -W., Kim, S., Tracy, J. B., Jasanoff, A. \& Bawendi, M. G. (2005). Inter- and intramolecular [4 +3] cycloadditions using epoxy enol silanes as functionalized oxyallyl cation precursors. J. Am. Chem. Soc., 127, 13, 4556-4557, ISSN 0002-7863

Kim, Y. -G., Oh, S. -K. \& Crooks, R. M. (2004). Preparation and characterization of 1-2 nm dendrimer-encapsulated gold nanoparticles having very narrow size distributions. Chem. Mater., 16, 1, 167-172, ISSN 0897-4756

Kugler, T., Lögdlund, M. \& Salaneck, W. R. (1998). Polymer surfaces and interfaces in lightemitting devices. IEEE J. Sel. Top. Quantum Electron., 4, 1, 14-23, ISSN 1077-260X

Kumar, A., Joshi, H., Pasricha, R., Mandale, A. B. \& Sastry, M., J. Phase transfer of silver nanoparticles from aqueous to organic solutions using fatty amine molecules. Colloid Interface Sci., 264, 2, 396-401, ISSN 0021-9797

Li, Y., Wu, Y. \& Ong, B. S. (2005). Facile synthesis of silver nanoparticles useful for fabrication of high-conductivity elements for printed electronics. J. Am. Chem. Soc., 127, 10, 3266-3267, ISSN 0002-7863

Manna, A., Imae, T. Aoi, K., Okada, M. \& Yogo, T. (2001). Synthesis of dendrimer-passivated noble metal nanoparticles in a polar medium: comparison of size between silver and gold particles. Chem. Mater., 13, 5, 1674-1681, ISSN 0897-4756

Mason, M. G., Hung, L. S., Tang, C. W., Lee, S. T., Wong, K. W. \& Wang, M. (1999). Characterization of treated indium-tin-oxide surfaces used in electroluminescent devices. J. Appl. Phys., 86, 3, 1688-1692, ISSN 0921-8979

Pan, S. \& Rothberg, L. J. (2005). Enhancement of platinum octaethyl porphyrin phosphorescence near nanotextured silver surfaces. J. Am. Chem. Soc., 127, 16, 60876094. ISSN 0002-7863

Park, J. W., Hllah, M. H., Park, S. S. \& Ha, C. S., (2007). Organic electroluminescent devices using quantum-size silver nanoparticles. J. Mater. Sci.: Mater. Electron., 18, 393-397. ISSN: 0957-4522

Pastoriza-Santos, I. \& Liz-Marzán, L. (2002). Synthesis of silver nanoprisms in DMF. Nano Lett., 2, 8, 903-905, ISSN 1530-6984

Pileni, M. P. (1998). Optical properties of nanosized particles dispersed in colloidal solutions or arranged in 2D or 3D superlattices. New J. Chem., 22, 7, 693-702, ISSN 1141-0546

Rele, M., Kapoor, S., Sharma, G. \& Mukherjee, T. (2004). Reduction and aggregation of silver and thallium ions in viscous media. Phys. Chem. Chem. Phys., 6, 3, 590-595, ISSN 1463-9076

Sun, Y. \& Xia, Y. (2002). Shape-controlled synthesis of gold and silver nanoparticles. Science, 298, 5601, 2176-2179, ISSN 0036-8075

Taubert, A., Wiesler, U. -M. \& Müllen, K. (2003). Dendrimer-controlled one-pot synthesis of gold nanoparticles with a bimodal size distribution and their self-assembly in the solid state. J. Mater. Chem., 13, 5, 1090-1093, ISSN 0959-9328

Wilson, O. M., Scott,R. W. J., Garcia-Martinez, J. C. \& Crooks, R. M.(2005). Synthesis, characterization, and structureselective extraction of 1-3-nm diameter AuAg dendrimer-encapsulated bimetallic nanoparticles. J. Am. Chem. Soc.,

Wilson, O. M., Scott, R. W. J., Garcia-Martinez, J. C. \& Crooks, R. M. (2005). J. Am. Chem. Soc., 127, 3, 1015-1024, ISSN 0002-7863 


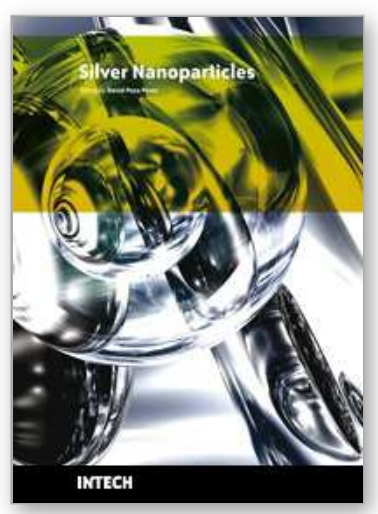

\author{
Silver Nanoparticles \\ Edited by David Pozo Perez
}

ISBN 978-953-307-028-5

Hard cover, 334 pages

Publisher InTech

Published online 01, March, 2010

Published in print edition March, 2010

Nanotechnology will be soon required in most engineering and science curricula. It cannot be questioned that cutting-edge applications based on nanoscience are having a considerable impact in nearly all fields of research, from basic to more problem-solving scientific enterprises. In this sense, books like "Silver Nanoparticles" aim at filling the gaps for comprehensive information to help both newcomers and experts, in a particular fast-growing area of research. Besides, one of the key features of this book is that it could serve both academia and industry. "Silver nanoparticles" is a collection of eighteen chapters written by experts in their respective fields. These reviews are representative of the current research areas within silver nanoparticle nanoscience and nanotechnology.

\title{
How to reference
}

In order to correctly reference this scholarly work, feel free to copy and paste the following:

Chang-Sik Ha, Jin-Woo Park and Habib Ullah (2010). O-Phenylenediamine Encapsulated Silver Nanoparticles and Their Applications for Organic Light-Emitting Devices, Silver Nanoparticles, David Pozo Perez (Ed.), ISBN: 978-953-307-028-5, InTech, Available from: http://www.intechopen.com/books/silver-nanoparticles/ophenylenediamine-encapsulated-silver-nanoparticles-and-their-applications-for-organic-light-emitti

\section{INTECH}

open science | open minds

\section{InTech Europe}

University Campus STeP Ri Slavka Krautzeka 83/A 51000 Rijeka, Croatia Phone: +385 (51) 770447 Fax: +385 (51) 686166 www.intechopen.com

\section{InTech China}

Unit 405, Office Block, Hotel Equatorial Shanghai No.65, Yan An Road (West), Shanghai, 200040, China 中国上海市延安西路65号上海国际贵都大饭店办公楼405单元 Phone: +86-21-62489820

Fax: +86-21-62489821 
(C) 2010 The Author(s). Licensee IntechOpen. This chapter is distributed under the terms of the Creative Commons Attribution-NonCommercialShareAlike-3.0 License, which permits use, distribution and reproduction for non-commercial purposes, provided the original is properly cited and derivative works building on this content are distributed under the same license. 